\title{
Metabolic Fates of Evening Crop-Stored Sugar in Ruby-Throated Hummingbirds (Archilochus colubris)
}

\author{
Erich R. Eberts ${ }^{1,2}{ }^{2}$, Morag F. Dick ${ }^{1}$ and Kenneth C. Welch Jr. ${ }^{1,2}$ \\ 1 Department of Biological Sciences, University of Toronto Scarborough, 1265 Military Trail, Toronto, \\ ON M1C 1A4, Canada; morag.dick@utoronto.ca (M.F.D.); kwelch@utsc.utoronto.ca (K.C.W.J.) \\ 2 Department of Ecological \& Evolutionary Biology, University of Toronto, 25 Willcocks Street, Toronto, \\ ON M5S 3B2, Canada \\ * Correspondence: erich.eberts@mail.utoronto.ca; Tel.: +1-416-208-5147
}

Received: 30 November 2018; Accepted: 5 January 2019; Published: 15 January 2019

\begin{abstract}
During the day, hummingbirds quickly metabolize floral nectar to fuel high metabolic demands, but are unable to feed at night. Though stored fat is the primary nocturnal metabolic fuel, it has been suggested that hummingbirds store nectar in their crop to offset fat expenditure in the night or to directly fuel their first foraging trip in the morning. We examine the use of crop-stored sugar in the nocturnal energy budget of ruby-throated hummingbirds (Archilochus colubris) using respirometry and ${ }^{13} \mathrm{C}$ stable isotope analysis. Hummingbirds were fed a ${ }^{13} \mathrm{C}$-enriched sugar solution before lights-out and held in respirometry chambers overnight without food. Respirometry results indicate that the hummingbirds metabolized the sugar in the evening meal in less than $2 \mathrm{~h}$, and subsequently primarily catabolized fat. Breath stable isotope signatures provide the key insight that the hummingbirds converted a substantial portion of an evening meal to fats, which they later catabolized to support their overnight metabolism and spare endogenous energy stores. These results show that the value of a hummingbird's evening meal depends on how much of this energy was converted to fat. Furthermore, this suggests that evening hyperphagia is an important energy maximization strategy, especially during energetically expensive periods such as migration or incubation.
\end{abstract}

Keywords: nocturnal energy management; hummingbirds; fuel-use; stable isotopes; respirometry; crop storage; metabolism; respiratory exchange ratio

\section{Introduction}

Small birds often face energy balance challenges because they metabolize the energy that they consume at very high rates, are unable to store large amounts of energy rich tissue, and quickly lose heat to their environment [1-3]. These organisms, such as hummingbirds, are often further energetically stressed at night, when they are unable to feed, often experience low ambient temperatures, and expend energy quickly [3-5]. Hummingbirds sustain their uniquely high energy requirements using various energy management strategies during both the day and night [6-8].

During the day, hummingbirds feed on high-energy floral nectar, hovering at and flying among flowers. They fuel the extremely high energetic demands of this activity by quickly metabolizing ingested sugar [9-12]. When food becomes unavailable, hummingbirds have the capacity to rapidly switch between exclusively directly oxidizing exogenous carbohydrates and exclusively catabolizing endogenous lipids [11]. At night, hummingbirds are generally not able to feed (though it has been speculated that some may attempt to feed under moonlight [13]), so they rely on energy stored during the day in order to fuel their metabolism overnight. They may also reduce their overnight energy expenditure by using torpor when they have low energy stores or when it is advantageous to conserve 
energy [14-17]. Fatty acids are the primary endogenous energy substrates that most small birds use to fuel their metabolism during long-term fasts [18]. Hummingbirds are expected to primarily use endogenous fat stores to fuel their metabolisms at night; however, their fat stores at the beginning of the night may be limited by aerodynamic, morphological, or environmental constraints $[17,19]$. It has also been suggested that hummingbirds are able to support nocturnal normothermy with carbohydrates by retaining nectar in their crop in the evening, and slowly metering out this energy "storage depot" during the night [19-21].

Many birds have a crop, which may be a permanent or temporary esophageal pouch that allows for postprandial food handling and mediation of food passage [22]. In hummingbirds, the rate that nectar empties from the crop may be influenced by factors including the rate of intestinal absorption, metabolic demand, meal and air temperature, and food availability [12,23-26]. Their crops may allow hummingbirds to vary their foraging strategy during the day, or to store a large meal subsequent to a final evening hyperphagia bout $[19,20,23,25]$. By directly oxidizing the entirety of this sugar, hummingbirds could maximize the amount of energy they gain from this meal, and avoid the $16 \%$ energetic cost associated with oxidation of lipids synthesized from ingested sugars [11]. By filling the crop before nighttime and fueling their nocturnal metabolism with sugar, hummingbirds could spare endogenous fat expenditure, or directly fuel the first foraging trip(s) in the morning $[19,20,25]$. Alternatively, hummingbirds may use the nectar in the crop to synthesize fatty acids while also directly fueling metabolism, in order to maximize lipid deposition [11,27].

Previous studies have used respiratory exchange ratio (RER), which is the ratio of the rate of carbon dioxide production $\left(\dot{V}_{\mathrm{CO}_{2}}\right)$ to the rate of oxygen consumption $\left(\dot{V}_{\mathrm{O}_{2}}\right)$, to characterize nocturnal fuel-use in hummingbirds $[17,20,21,28]$. Since carbohydrate and lipid oxidation consume different amounts of $\mathrm{O}_{2}$ per molecule of $\mathrm{CO}_{2}$ produced, RER may be used to indicate what type of substrate is being metabolized, with an RER $\sim 1.0$ indicating carbohydrate oxidation and $\sim 0.7$ for lipids $[29,30]$. RERs exceeding 1 may reflect lipogenesis, or other factors such as hyperventilation or increase of antioxidant potential, and intermediate values suggest simultaneous metabolism of carbohydrates, proteins, and/or lipids [29-31]. Studies that have measured the exchange of respiratory gasses in sleeping hummingbirds found ambiguous nighttime RERs, which indicated that the hummingbirds metabolized both exogenous carbohydrate and endogenous lipid stores for a substantial portion of the night $[20,21]$. These results are contrary to expectations that fat is exclusively metabolized at night, and are possibly confounded by food availability and low temporal resolution, so exactly how evening hyperphagia is used to fuel nighttime fasts is still unclear $[17,28]$. Furthermore, the metabolic fate of an evening meal is not fully illuminated by RER because while it may be used to suggest the classes of substrates being oxidized, these inferences are based on possibly tenuous assumptions and the significance of RER values between or outside the 0.7 to 1.0 range are not fully understood. Additionally, RER does not necessarily identify from where these substrates originate [29,30]. When RER $>1$, this indicates potential for lipogenesis and that not all sugar is directly oxidized; however, it is not clear what proportion of this sugar is used for lipogenesis or is directly oxidized by examining RER alone. By evaluating both RER and the ${ }^{13} \mathrm{C}$ stable isotope signature of a hummingbird's breath, we would be able to estimate the amount of energy in the last meal that was converted to and later catabolized as fat, and amount of sugar that was directly oxidized.

We coupled respirometry and ${ }^{13} \mathrm{C}$ stable isotope analysis in order to track the specific metabolic fate of a final evening meal and quantify its contribution to the overnight energy expenditure of ruby-throated hummingbirds (Archilochus colubris). We predicted that to maximize their potential energy gain and spare the maximum amount of lipid stores, the hummingbirds that consumed a large meal prior to lights-out would primarily directly oxidize this crop-stored sugar before metabolizing fat stores as the primary fuel for the rest of the night. Respiratory exchange ratios (RER) and breath stable isotope signatures $\left(\delta^{13} \mathrm{C}\right)$ indicate that the hummingbirds metabolized labeled sugar for less than $2 \mathrm{~h}$ and converted a portion of the energy in the last meal to fat. In the last $9 \mathrm{~h}$ of the night, in addition to catabolizing endogenous fat reserves, they used lipids synthesized from sugars in the last meal 
to partially fuel their metabolism. In general, we suggest that evening hyperphagia is an important energy maximization strategy, especially during energetically expensive periods such as migration.

\section{Materials and Methods}

\subsection{Study Animals}

Adult male Archilochus colubris ( $\mathrm{n}=6$; mass range: $3.4-5.9 \mathrm{~g}$ ) were captured with a modified box trap (drop door trap) in Toronto, ON, Canada, at the University of Toronto Scarborough (UTSC). Captive hummingbirds were housed individually in EuroCage enclosures, measuring $91.5 \mathrm{~cm} \mathrm{~W} \times$ $53.7 \mathrm{~cm} \mathrm{H} \times 50.8 \mathrm{~cm} \mathrm{D}$, in the UTSC vivarium. Once captive, birds were fed ad libitum on a $20 \%(w / v)$ solution of a 3:1 Nektar-Plus and sucrose mix (Guenter Enderle, Tarpon Springs, FL, USA). Birds were subjected to a 13-h light/11-h dark photoperiod, with the dark period starting at 21:30 h, and the light period starting at $8: 30 \mathrm{~h}$. This photoperiod is reflective of their natural winter photoperiod, as the data were collected in the late winter and early spring; the birds were not in breeding condition during the experimental period. Details of animal husbandry and all experiments were approved by the University of Toronto Animal Care Committee (protocol \# 20011649) and permitted by the Canadian Wildlife Service (\# CA 0258).

\subsection{Experimental Protocol}

Data collection was conducted in an acrylic enclosure, measuring $10 \mathrm{~cm} \mathrm{~W} \times 10 \mathrm{~cm} \mathrm{H} \times 10 \mathrm{~cm} \mathrm{D}$, with a perch available to the hummingbird in a position that it could easily access a feeding syringe. The feeding syringe was attached to a magnet and affixed to the side of the chamber via a magnet on the outside of the chamber. The placement of the syringe was adjusted into a position inaccessible to the hummingbird by moving the magnets, without opening the chamber. An IR sensitive video monitoring camera (YI Home Camera, Yi Technology, China, 2017) was used to track activity patterns while the bird was in the chamber.

Prior to data collection, birds were trained to feed from the adjustable feeding syringe while in the respirometry chamber to ensure that they were willing and able to feed ad libitum during the evening portion of each "fed" trial. Data collection took place between February 2018 and April 2018 between 20:30 $\mathrm{h}$ and 9:00 h, one hour before lights-out and $30 \mathrm{~min}$ after lights-on. Data collection began in the evening following a 30-min period of food deprivation, which ensured that the hummingbirds would willingly feed in the respirometry chamber. Hummingbirds were hand-fed a ${ }^{13} \mathrm{C}$-enriched sucrose solution $\left(\delta^{13} C_{\text {exogenous }}=+24.3 \pm 0.2 \%\right.$, D-Sucrose (Glucose-13C6, 98\%, Cambridge Isotope Laboratories, Andover, MA, USA)) immediately before being placed into the respirometry chamber where they were also able to feed on the labeled solution until lights-out, when the feeding syringe was moved to an inaccessible position. The isotopic signature of this acute sugar meal was distinct from that of their maintenance diet $\left(\delta^{13} C_{\text {maintenence }}=-17.5 \pm 0.3 \%\right.$ ). Fed birds consumed an average of $0.8 \pm 0.1 \mathrm{~mL}$ of $20 \%$ sucrose solution. This meal contained $470.0 \pm 55.4 \mu \mathrm{mol}$ of sucrose and had an energy content of approximately $2651 \pm 313 \mathrm{~J}$. Additionally, each bird was subject to a fasted trial, in which they were food deprived in the evening at least $1 \mathrm{~h}$ before lights-out. Lights were gradually dimmed for a 30-min period before 21:30 h, remained totally dark for $11 \mathrm{~h}$, and were gradually turned on for $30 \mathrm{~min}$ starting at 8:30 h. Air temperature was measured directly outside the chamber via a thermoresistor and ranged from $23-26^{\circ} \mathrm{C}$; although air temperature inside the chamber was not recorded, separate experiments show the inside and outside air temperatures were within $1^{\circ} \mathrm{C}$.

\subsection{Respirometry}

Oxygen consumption and carbon dioxide production rates overnight were obtained via push-flow respirometry using a TurboFOX5 (TurboFOX5; Sable Systems International, Las Vegas, NV, USA). Air was flowed into the chambers through Bev-a-line tubing at a rate of $300 \mathrm{~mL} / \mathrm{min}$. The excurrent airstream was subsampled at $\sim 100 \mathrm{~mL} / \mathrm{min}$. Sub-sampled air first passed through the TurboFOX5's 
water vapour meter module, which measured water vapour pressure (kPa) (TurboFOX5; Sable Systems International). The air was then passed through the integrated carbon dioxide gas analyser (infrared), and subsequently through a column containing indicating Drierite (W.A. Hammond DRIERITE, Xenia, $\mathrm{OH}, \mathrm{USA}$ ) for the removal of water vapour before entering into the oxygen analyser (fuel cell). Analogue voltage output from the thermoresistor, oxygen and carbon dioxide analysers, flow meter, water vapour pressure and in-line barometric pressure sensors were recorded at $1 \mathrm{~s}$ intervals over the duration of the trial $(13 \mathrm{~h}$ ) using EXPEDATA software (v. 1.8.4; Sable Systems International) and were recorded on a laptop computer via the on-board A/D converter through the serial output of the TurboFOX5.

Raw data were corrected to standard temperature and pressure and rates of oxygen consumption $\left(\dot{V}_{\mathrm{O}_{2}}\right)$ and carbon dioxide production $\left(\dot{V}_{\mathrm{CO}_{2}}\right)$, and respiratory exchange ratios (RER) were calculated in Expedata using standard equations ([30]; equations 10.6, 10.7, respectively). The rate of oxygen consumption $\left(\dot{V}_{o_{2}}\right)$ and the oxyjoule equivalent (sensu Lighton et al. [32]) were used to calculate the metabolic rate of each 10-min time-period $\left(E_{\text {rate }}, \mathrm{J} / \mathrm{min}\right)$, according to the following equation:

$$
E_{\text {rate }}=\left(16+5.164 * R E R_{\text {bound }}\right) * \dot{V}_{o_{2}}
$$

where $R E R_{\text {bound }}$ is the average RER for each 10-min time-period, confined to 0.71 and 1.0; $\dot{V}_{o_{2}}$ is the average oxygen consumption rate $\left(\mathrm{mL} \mathrm{O}_{2} / \mathrm{min}\right)$ of each 10-min time-period; and the oxyjoule equivalent has the units of $\mathrm{J} / \mathrm{mL} \mathrm{O}_{2}$ [30]. Total nighttime and substrate-specific energy expenditures were calculated by integrating the metabolic rate $\left(E_{\text {rate }}\right)$ over time.

\subsection{Stable Carbon Isotope Analysis}

Carbon stable isotope analysis of the excurrent $\mathrm{CO}_{2}$ from the chambers, and liquid samples (maintenance diet and sucrose solution) were done using cavity ring-down spectroscopy (Picarro G2201-i Analyzer, Picarro Inc., Santa Clara, CA, USA). For the liquid samples, a $5 \mu \mathrm{L}$ sample was loaded into a tin capsule (Costech Analytical Technologies Inc., Valencia, CA, USA) with approximately $0.5 \mathrm{mg}$ of celite (Costech Analytical Technologies Inc.), and these samples were combusted using the Combustion Module (Picarro Inc.) connected to the analyzer. To determine exhaled $\mathrm{CO}_{2}$ stable isotope signature, we directly subsampled excurrent air from the chamber. We report $\delta^{13} \mathrm{C}$ on a per mil $(\%)$ basis relative to the international carbon standard, Vienna Pee Dee Belemnite (VPDB) [33], where:

$$
\delta^{13} C=\frac{\left({ }^{13} C /{ }^{12} C\right)_{\text {sample }}-\left({ }^{13} C /{ }^{12} C\right)_{\text {standard }}}{\left({ }^{13} C /{ }^{12} C\right)_{\text {standard }}} * 1000 .
$$

Because the sampled air contained a mixture of breath and ambient $\mathrm{CO}_{2}$, the isotopic signature of exhaled breath $\left(\delta^{13} C_{\text {breath }}\right)$ was determined through the use of the two-part concentration-dependent mixing model adapted from Phillips \& Koch (2002), such that:

$$
\delta^{13} C_{\text {breath }}=\frac{\left[\delta^{13} C_{\text {sampled }}-\delta^{13} C_{a m b i e n t}\left(f_{a}\right)\right]}{\left(1-f_{a}\right)}
$$

where $\delta^{13} C_{\text {sample }}$ is the isotopic signature of air excurrent from the chamber; $\delta^{13} C_{\text {ambient }}$ is the isotopic signature of ambient air; and $f_{a}$ is the fraction of $\mathrm{CO}_{2}$ in the sampled air from ambient air [34]. Next, the proportion of expired $\mathrm{CO}_{2}$ supported by exogenous labelled carbohydrates $\left(f_{\text {exo }}\right)$ was calculated as in Welch and Suarez (2007) for each 10-min time-period, such that:

$$
f_{\text {exo }}=\frac{\left(\delta^{13} C_{\text {breath }}-\delta^{13} C_{\text {endogenous }}\right)}{\left(\delta^{13} C_{\text {exogenous }}-\delta^{13} C_{\text {endogenous }}\right)},
$$


where $\delta^{13} C_{\text {breath }}$ is the isotopic signature of exhaled breath; $\delta^{13} C_{\text {endogenous }}$ is the average isotopic signature measured during the fasted trial; and $\delta^{13} C_{\text {exogenous }}$ is the isotopic signature of the labeled sucrose solution [35]. This proportion was used to calculate the rate of tracer oxidation $\left(M_{\text {rate }}\right.$, in $\mu \mathrm{mol} / \mathrm{min}$ ) of each $10-\mathrm{min}$ time block, such that:

$$
M_{\text {rate }}=f_{\text {exo }} * \frac{\dot{V}_{o_{2}}}{1000 * 22.4} * \frac{10^{6}}{n}
$$

where $\dot{V}_{\mathrm{O}_{2}}$ is the oxygen consumption rate $\left(\mathrm{mL} \mathrm{O}_{2} / \mathrm{min}\right) ; n$ is the number of carbons in the labeled sugar (12); and 22.4 is the amount, in moles, of oxygen in each liter of air at standard temperature and pressure. $M_{\text {rate }}$ was then converted to $\mathrm{J} / \mathrm{min}$, assuming $1 \mathrm{~g}$ of sucrose contains approximately $0.1648 \mathrm{~J}$. Cumulative nighttime and substrate-specific tracer oxidations were calculated by integrating the $M_{\text {rate }}$ over time.

\subsection{Data Processing and Analysis}

Expedata was used to temporally align the raw respirometry and stable isotope data, and to perform calculations for $\dot{V}_{\mathrm{O}_{2}}, \dot{V}_{\mathrm{CO}_{2}}, R E R, \delta^{13} \mathrm{C}, \delta^{13} \mathrm{C}_{\text {breath }}$ and $f_{\text {exo }}$ (v. 1.8.4; Sable Systems International). $\mathrm{R}$ was used to interpolate across baseline periods, perform the energy expenditure and tracer oxidation calculations, and to perform comparative and statistical analyses ( $\mathrm{R} \mathrm{v.} \mathrm{3.4.3;} \mathrm{Development} \mathrm{Core}$ Team, 2017). We first interpolated across baseline dwells, including three minutes before and after each specific marker placed at the beginning and end of each baseline. The resultant dataset was then aggregated (averaged) into 10-min time periods for each trial, with time 0 starting when the hummingbird took its last feed. Data was interpolated for time points that were missing due to baseline gaps using the 'na.spline' function (R package 'zoo' v1.8-4) with a natural cubic spline.

In order to evaluate the effects of a last meal and body mass on cumulative overnight energy expenditure, a linear mixed effects model was built, using the 'lme' function in the R package 'nlme' (v. 3.1-131), incorporating the availability of a last meal (fed or fasted) and evening body mass as fixed variables, and bird ID as a random variable. The time periods when metabolism was fueled by carbohydrates, lipids, or mixed fuels, and when lipogenesis was occurring, were determined by the average RER of each 10-min period. Time points where RER $\geq 1.0$ were categorized as lipogenesis and carbohydrate oxidation, $1.0>$ RER $\geq 0.9$ were categorized as carbohydrate oxidation, $0.9>\operatorname{RER} \geq 0.8$ were categorized as mixed fuel oxidation, and RER $<0.8$ were categorized as lipid catabolism. Though these thresholds do not allow for quantification of fuel types, they allowed for comparisons between periods of primarily one type of fuel usage. The RER ranges were cross referenced with $E_{\text {rate, }}$, and $M_{\text {rate }}$ to determine energy expenditure and tracer oxidation during the entire night and during each substrate-specific period. These data allowed us to estimate how much of the last meal was metabolized overnight, and the amount of energy in the last meal that was metabolized as either fat or sugar. Data are presented as mean \pm standard error, unless otherwise indicated, and significance was taken at $\alpha<0.05$.

\section{Results}

\subsection{Energy Expenditure and Respiratory Exchange Ratios}

After an initial peak upon being placed in the chambers, metabolic rates $(\mathrm{J} / \mathrm{min})$ declined at the time of lights-off and remained stable throughout the night (fed: $10.36 \pm 0.09 \mathrm{~J} / \mathrm{min}$; fasted: $11.56 \pm 0.11 \mathrm{~J} / \mathrm{min}$ ) (Figure 1). These values reflect normothermic, sleeping metabolisms, as they are similar to the metabolic rates previously measured in resting, post-absorptive, normothermic ruby-throats in the dark $(4.707 \mathrm{~J} / \mathrm{min})$ [16], and lower than those of perch-feeding ruby-throats $(23.70 \mathrm{~J} / \mathrm{min})$ [36]. Video recordings of the birds showed fidgeting throughout the night, further confirming that these birds did not enter torpor on any trials. The average total nighttime energy expenditure (fasted: $7640 \pm 481 \mathrm{~J}$; fed: $6806 \pm 405 \mathrm{~J}$ ) were not significantly different between fed and fasted trials, when accounting for body mass as a covariate $(p=0.16)$. 


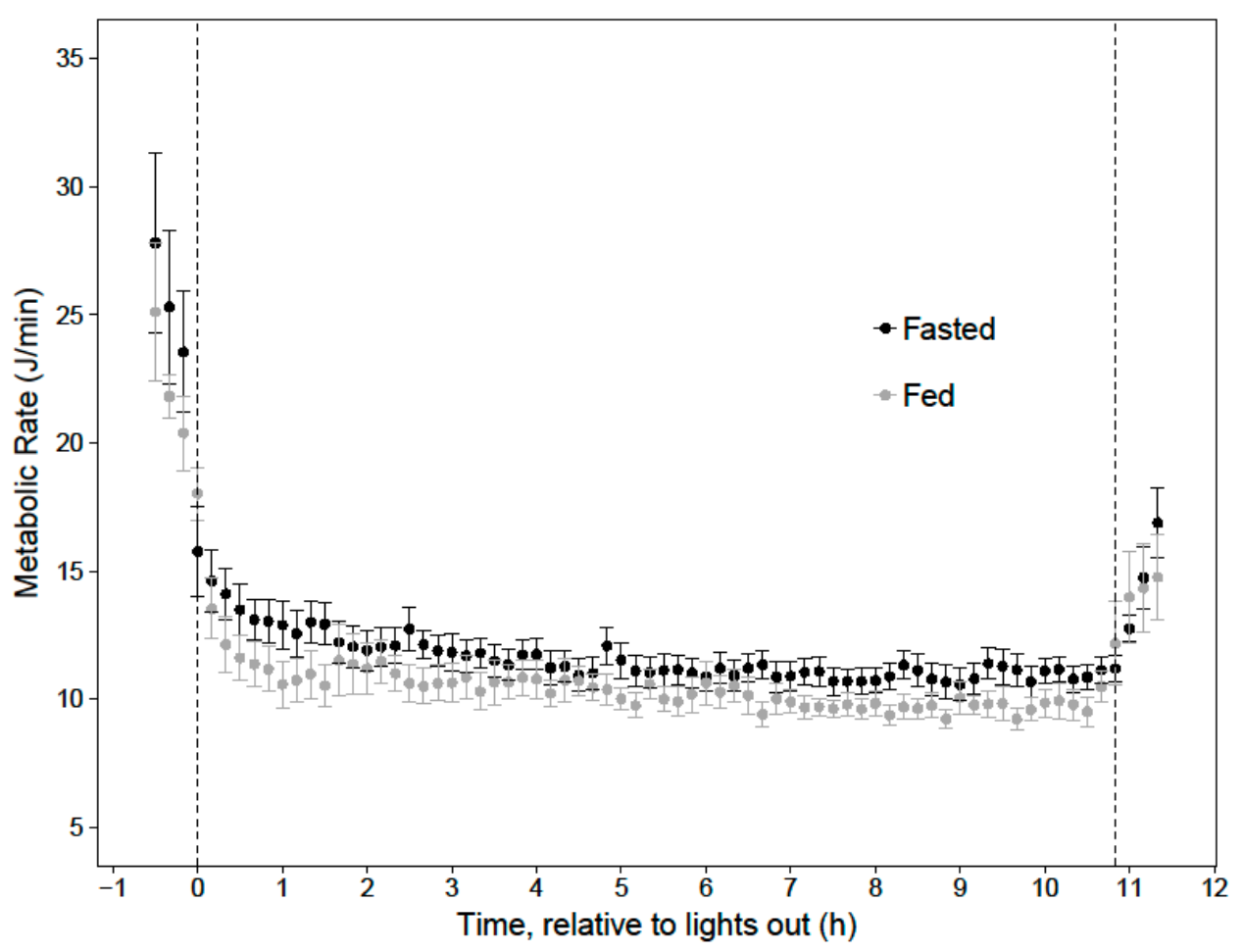

Figure 1. Overnight metabolic rates $(\mathrm{J} / \mathrm{min})$ exhibited by ruby-throated hummingbirds in fed and fasted trials, relative to the time of lights-out (time $=0$ ). Vertical dashed lines indicate time of lights off and on. Data are presented as mean \pm SEM of 10-min bins averaged across the individual birds $(n=6)$.

In the fasted trials, overnight RER remained consistently low $(0.68 \pm 0.02)$ for the entire night $(11.0 \mathrm{~h} \pm 0.0 \mathrm{~h})$. In the fed trials, RER peaked at $1.28 \pm 0.09$ at the time of the last meal and declined for the following $2 \mathrm{~h}$ until stabilizing for the remainder of the night (Figure 2). In the first hour $(1.0 \pm 0.2 \mathrm{~h}$ ), following the last meal, the RER exceeded 0.90 , and in the second hour $(1.0 \pm 0.5 \mathrm{~h})$ it was between 0.90 and 0.80 . The RER remained below 0.80 for the rest of the night $(8.9 \mathrm{~h} \pm 0.7 \mathrm{~h})$. The combined energy expenditure during the first two hours was less than $20 \%$ of the overnight energy expenditure, and conversely, the energy expenditure when the RER was less than 0.80 accounted for about $80 \%$ of the total energy expenditure (Table 1).

Table 1. Energy Expenditure during periods of selected RER ranges in fed trials.

\begin{tabular}{ccccc}
\hline & Total & RER $>\mathbf{0 . 9}$ & $\mathbf{0 . 9}>$ RER $>\mathbf{0 . 8}$ & RER $<\mathbf{0 . 8}$ \\
\hline RER average $_{\text {Energy Expenditure }(\mathrm{kJ})}$ & $0.77 \pm 0.02^{1}$ & $1.09 \pm 0.04$ & $0.84 \pm 0.01$ & $0.72 \pm 0.01$ \\
Time (h) & $6806 \pm 405^{2}$ & $692.9 \pm 100.5$ & $599.9 \pm 297.1$ & $5514 \pm 620.8$ \\
Percent of Nighttime Energy Expenditure (\%) & 100 & $10.4 \pm 1.8$ & $9.4 \pm 5.1$ & $80.2 \pm 6.4$ \\
& 11 & $1.0 \pm 0.2$ & $1.0 \pm 0.5$ & $8.9 \mathrm{~h} \pm 0.7$ \\
\hline
\end{tabular}

${ }^{1}$ Average overnight RER in fasted trials was $0.68 \pm 0.02 .{ }^{2}$ Total energy expenditure in fasted trials was $7640 \pm 481 \mathrm{~J}$. All values are reported as mean $\pm \operatorname{SEM}(n=6)$. 


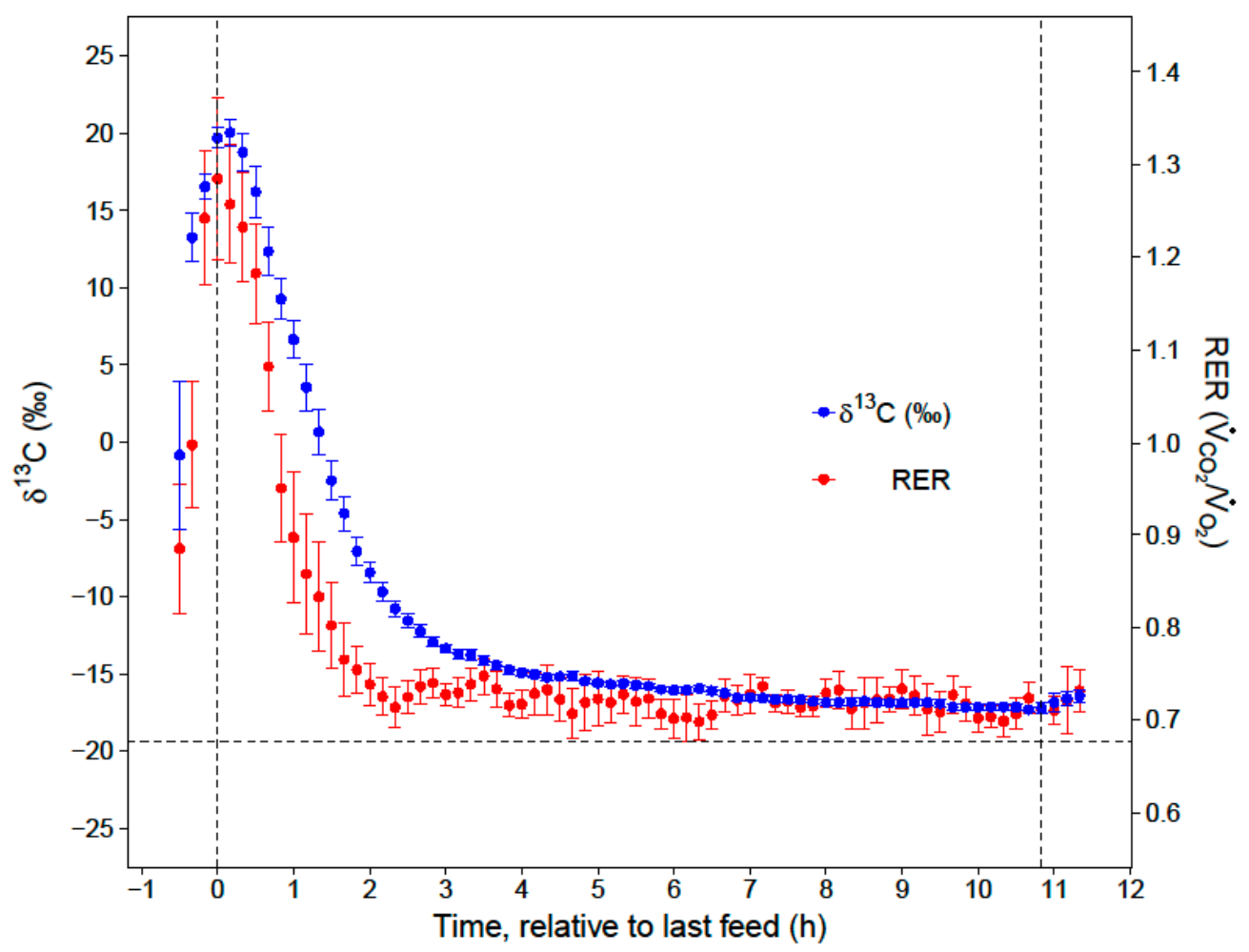

Figure 2. Overnight ${ }^{13} \mathrm{C}$ signature $\left(\delta^{13} \mathrm{C} \%\right.$; blue) and RER (red) of fed trials exhibited by ruby-throated hummingbirds, relative to the time of the last feeding (time $=0$ ), which was, on average, 10 min prior to lights out. The horizonal dashed line indicates the average nighttime ${ }^{13} \mathrm{C}$ signature and RER in fasted trials. Vertical dashed lines indicate time of lights off and on. Data are presented as mean \pm SEM of 10-min bins averaged across the individual birds $(n=6)$.

\subsection{Instantaneous and Cumulative Tracer Oxidation}

In the fasted trials, the average overnight $\delta^{13} \mathrm{C}$ signature $(-19.4 \pm 0.03 \%)$ was reflective of the catabolism of endogenous energy stores derived from the maintenance diet. In the fed trials, the $\delta^{13} \mathrm{C}$ signature peaked at $20.0 \pm 0.8 \%$ in the second 10-min period following the last meal and declined to a minimum of $-17.3 \pm 0.2 \%$ o throughout the night (Figure 2). Likewise, the rate of labeled carbohydrate oxidation in each 10-min period $\left(M_{\text {rate }}\right)$ peaked at $18.18 \pm 1.19 \mathrm{~J} / \mathrm{min}$ at the time of lights-out and decreased to a minimum value of $4.655 \pm 0.412 \mathrm{~J} / \mathrm{min}$ by the time of lights-on (Figure 3). The cumulative oxidation of exogenous energy steeply increased in the first two hours of the night and continued to gradually increase until morning to a maximum of $2040 \pm 119 \mathrm{~J}$ (Figure 4).

On average, birds consumed $2651 \pm 313 \mathrm{~J}$ of oxidizable energy as exogenous sugar within $45 \mathrm{~min}$ before lights out, and $27.2 \pm 2.4 \%$ of the energy in this meal was metabolized while the birds fed in the evening. Approximately half of the energy in the evening meal was metabolized during the nighttime (Table 2). Of this amount of exogenous energy metabolized during the night, about $40 \%$ was oxidized during the first hour, when RER was greater than 0.9 , and $10 \%$ was accounted for during the second hour when RER was between 0.9 and 0.8. Nearly half of this was metabolized during the period the RER was less than 0.8. These fuels accounted for similar proportions of total overnight energy expenditure, but the proportion of metabolism that was supported by exogenous energy declined between each period of the night. 


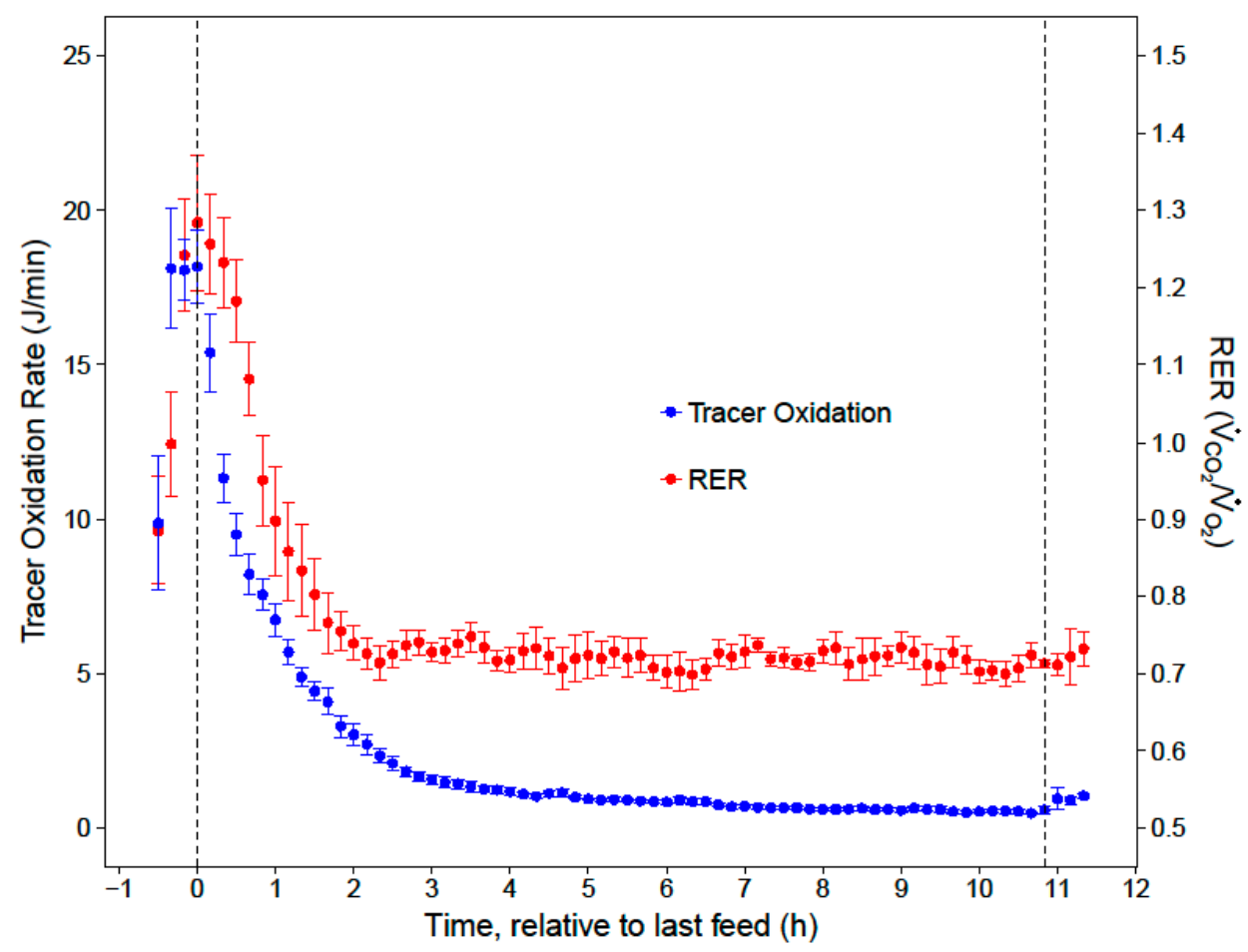

Figure 3. Average overnight instantaneous ${ }^{13} \mathrm{C}$ tracer oxidation rates $(\mathrm{J} / \mathrm{min}$; blue), and RER (red) exhibited by ruby-throated hummingbirds in fed trials. Time is relative to the time of the last feeding (time $=0$ ), which was, on average, 10 min prior to lights out. Vertical dashed lines indicate time of lights off and on. Data are presented as mean \pm SEM of 10-min bins averaged across the individual birds $(n=6)$.

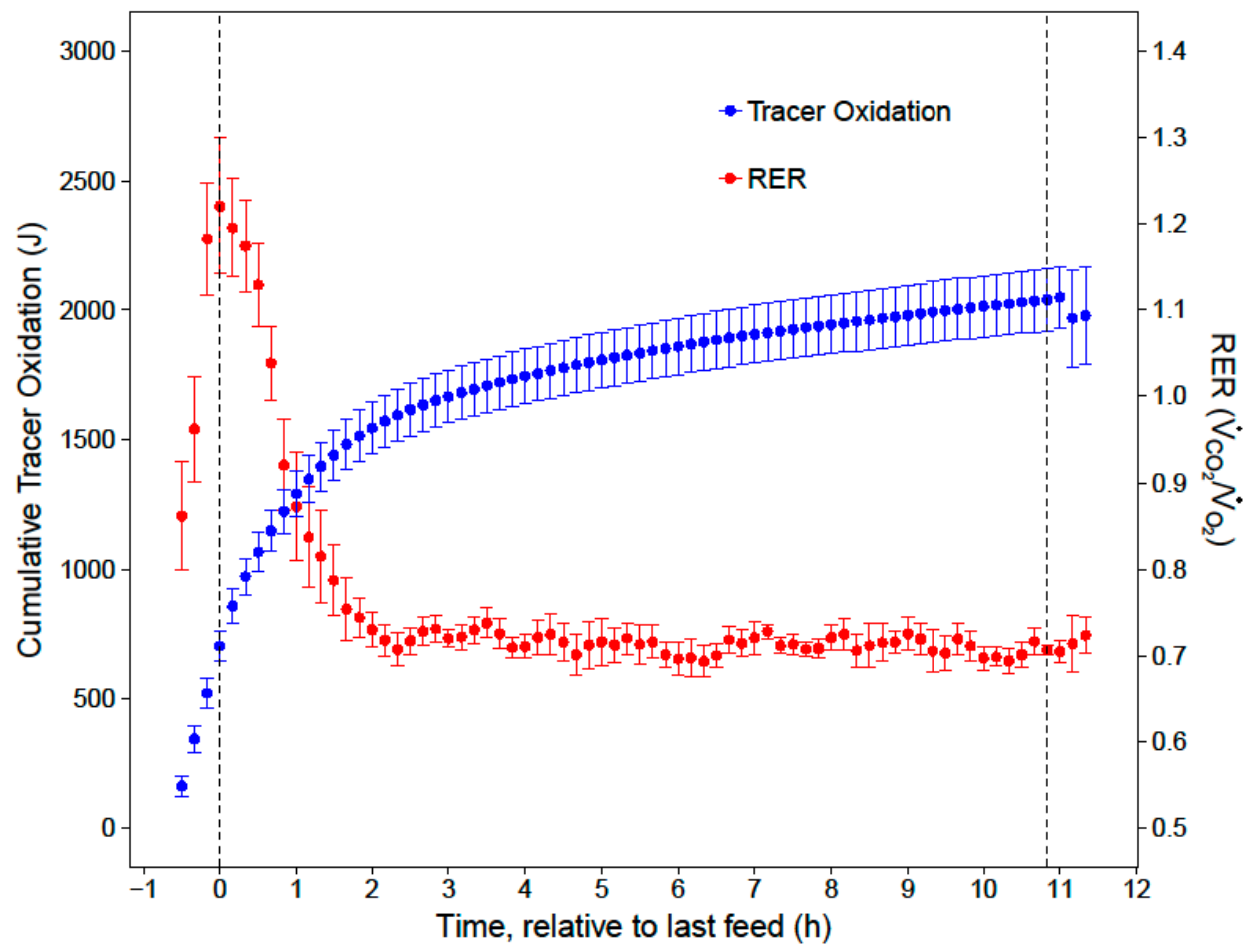

Figure 4. Average overnight cumulative ${ }^{13} \mathrm{C}$ tracer oxidation (J; blue), and RER (red) exhibited by ruby-throated hummingbirds in fed trials. Time is relative to the time of the last feeding (time $=0$ ), which was, on average, $10 \mathrm{~min}$ prior to lights out. Vertical dashed lines indicate time of lights off and on. Data are presented as mean \pm SEM of 10 -min bins averaged across the individual birds $(n=6)$. 
Table 2. Tracer oxidation during periods of selected RER ranges in fed trials.

\begin{tabular}{ccccc}
\hline & Total & RER $>\mathbf{0 . 9}$ & $\mathbf{0 . 9}>$ RER $>\mathbf{0 . 8}$ & RER $<\mathbf{0 . 8}$ \\
\hline Amount of Tracer Oxidation (kJ) & $1276 \pm 91^{1}$ & $512.2 \pm 56.6$ & $131.4 \pm 38.0$ & $632.2 \pm 91.9$ \\
Percentage of Energy in Last Meal (\%) & $51.2 \pm 5.7$ & $21.2 \pm 4.6$ & $6.5 \pm 2.6$ & $23.4 \pm 3.4$ \\
Percentage of Cumulative Oxidation (\%) & $100.0 \pm 0.0$ & $40.5 \pm 4.6$ & $10.4 \pm 3.0$ & $49.1 \pm 6.2$ \\
Percentage of Nighttime Energy Expenditure (\%) & $18.8 \pm 0.9$ & $7.7 \pm 1.0$ & $1.9 \pm 0.6$ & $9.1 \pm 1.1$ \\
Percentage of Substrate-Specific Energy Expenditure (\%) & - & $76.1 \pm 3.6$ & $34.4 \pm 7.5$ & $11.1 \pm 0.7$ \\
\hline
\end{tabular}

${ }^{1}$ Average energy content of evening meal: $2651 \pm 313 \mathrm{~J}$. All values are reported as mean \pm SEM $(n=6)$.

\section{Discussion}

Hummingbirds may endure overnight fasts by fueling their nocturnal metabolism with any nectar stored in their crop at the beginning of the night, and with endogenous fat synthesized during the day. We fed hummingbirds an isotopically-labeled evening meal and tracked how this evening meal was metabolized during the night. Our respirometry and stable isotope analyses substantiate our predictions that hummingbirds would quickly metabolize a large evening meal and that the energy in this meal would fuel a substantial portion of the overnight metabolism. Furthermore, they importantly allowed us to quantify the percentages of the last meal that were directly oxidized as carbohydrates, or later catabolized as fat.

During the first hour of the night $(\mathrm{RER}=1.09 \pm 0.04)$, the carbohydrates in the last meal were oxidized to support immediate energy demand or used for lipogenesis to build fat stores that supported metabolism later in the night. Surprisingly, a larger portion of the evening meal was used in lipogenesis and later catabolized as fat, instead of being directly oxidized completely to $\mathrm{CO}_{2}$ and $\mathrm{H}_{2} \mathrm{O}$ as carbohydrates. In the second hour of the night, hummingbirds exhibited a rapid switch from primarily carbohydrate oxidation to primarily fat catabolism (RER $=0.84 \pm 0.01$ ). These results are in contrast with Powers (1991), which showed RER values above 0.85 over $4 \mathrm{~h}$ into the night, for Anna's (4.5 g) and Costa's (3 g) hummingbirds [20]. After the first two hours of the night, low and stable RERs indicated that the hummingbirds primarily catabolized fat for the remainder of the night $(R E R=0.72 \pm 0.01)$. While our respirometry data show that sugar passed through the crop within two hours of the last feed, stable isotope analyses provide the key insights that the hummingbirds converted a substantial portion (23\%) of the evening meal to fat, and that this energy accounted for a substantial portion of lipid catabolism in the last $9 \mathrm{~h}$ of the night $(11 \%)$.

When hummingbirds consume a large meal in the late evening, the energy in this last meal may support approximately $19 \%$ of their total nighttime energy expenditure for an $11-\mathrm{h}$ night. Since overnight energy expenditure did not significantly differ between fed and fasted trials, birds that fed on an evening meal expended less endogenous energy stores overnight, compared to when they did not feed in the evening. This supports previous hypotheses that an evening meal could support a significant portion of overnight energy expenditure and spare endogenous fuel stores $[19,20,25]$. Previous studies have estimated that large meals stored in the crop could support from $4 \mathrm{~h}$ [25], to an entire night's [19] energy budget; however, this depends meal size (crop volume), nectar concentration, and how much of this meal is converted to fat. For example, Calder (1990) estimated that by consuming a large meal (170\% of the estimated crop volume [25]) of high concentration (38\%) nectar, a bird could fuel its entire overnight metabolism with the energy in this last meal (6600 J) [19]. If the concentration of this nectar were lower or the bird consumed less nectar, the value of the meal would be lessened. Because the meal size of each bird varied, we performed simple correlation tests to evaluate how the sizes of the last meals were correlated with peak RER values and the durations that the RERs were above 0.9 . These showed that the amounts of energy in the last meals were not significantly correlated with peak RER values ( $p=0.57)$ or the durations that the RERs were above $0.9(p=0.75)$. This suggests that the rates of lipogenesis and crop-emptying may be more important factors in determining how hummingbirds use evening meals, though we may lack statistical power to detect potential effects due to small sample size. Partial conversion of an evening meal into lipids, assuming an $84 \%$ efficiency of fatty acid synthesis, suggests that the meal may not support as much of the overnight metabolism as 
initially calculated [11]. In the present study, the average evening meal consisted of $2651 \mathrm{~J}$, though some of this energy was metabolized during the evening. If all of this meal was available at lights out and it were entirely directly oxidized, it would have accounted for $40 \%$ of the total overnight energy expenditure, or 33\% if it were entirely converted to fat. If about half of the carbohydrates in the last meal were converted to fat, the total energy contribution to overnight expenditure would be about $36.5 \%$. Thus, the degree of lipogenic activity may be an important factor in quantifying the energetic value of an evening meal. It is important to note, however, that in the present study we only tracked labeled carbon atoms from the glucose, not the fructose carbons, but it is unclear if glucose and fructose have different metabolic fates [37]. For example, studies in mammals suggest that glucose is preferentially used for lipogenesis [38]. If this pattern is similar in hummingbirds, by tracking only glucose, our estimations of how much of the last meal is directly oxidized or converted to fat could be slightly underestimated and overestimated, respectively. While further research is needed to clarify the specific metabolic fates of glucose and fructose, this caveat does not discount our observations that much of the evening meal is used for lipogenesis and is catabolized later in the night.

While our conclusions agree with the hypothesis that hummingbirds are able to support a significant portion of nighttime energy expenditure by consuming an evening meal, our study does not support the use of the crop as a 'storage depot' that could be drawn upon well into the night $[20,25]$. Our results suggest that as hummingbirds ingest an evening meal, they are not able to acutely slow the passage of nectar through the crop, and so they store the majority of this energy as fat in order to reserve it for later in the night. As hummingbirds settle in at their nighttime roosts, the energetic demand of highly active tissues (i.e., flight muscles) is reduced, so much of the circulating sugar is taken up by hepatic tissue and converted to lipids [11]. As these recently synthesized lipids in the liver are more readily mobilized, they appear to be catabolized before fats stored in endogenous adipose tissue; as a result, endogenous fat stores may be spared [39]. Thus, in the beginning of the night, by directly oxidizing carbohydrates in the last meal to fuel their immediate metabolic needs and converting a large portion of these carbohydrates to lipids, hummingbirds are able to fuel their short-term energy demands and prepare for energy shortages later.

Evening hyperphagia enables hummingbirds to maximize the amount of nectar in the crop at the start of fasting period, which could have beneficial effects during energetically demanding periods such as migration or breeding seasons. First, environmental and ecological restraints may not allow some hummingbirds to synthesize adequate fat stores to survive the nocturnal fast $[15,40]$. In such situations, these individuals could resort to torpor in order to reduce their overnight energy expenditure, or they could fill their crop before nighttime $[15,19]$. Evening hyperphagia may be especially useful during energetically expensive periods, such as incubation or moulting, when torpor may be detrimental $[14,15,41]$. In addition, migrating hummingbirds that maximize their evening crop contents would spare endogenous fat stores and maximize lipid stores [6,23]. By combining energy minimization (i.e., torpor) and energy maximization (i.e., evening hyperphagia) strategies, migrating hummingbirds could accumulate high endogenous fat stores, which are required to fuel long-term flights [42].

Overall, this study confirms that an evening nectar meal is an important factor in hummingbirds' overnight energy budget management $[19,20,25]$. By combining respirometry and stable isotope techniques, we were able to quantify how an evening meal was used during the night; either method individually would not clearly track the metabolic fate of this meal. Contrary to our expectations that sugar in the last meal would be entirely directly oxidized, a substantial portion was converted to fats and used later in the night. This information may be of value for future work investigating the various strategies hummingbirds employ to balance their daily energy budgets in various ecological and seasonal contexts.

Author Contributions: E.E., M.D., and K.W. contributed to project conceptualization and experimental design. E.E. and M.D. performed data collection, curation, analysis, and visualization. E.E. prepared original drafts and M.D. and K.W. reviewed and edited the final manuscript. K.W. provided supervision, resources, and funding. 
Funding: This research was supported by grants from the Natural Sciences and Engineering Research Council of Canada Discovery Grant (number 386466) and the Human Frontier Science Program (number RGP0062/2016).

Acknowledgments: We thank Yazan Shamli Oghli for assistance with overnight data collection. We also thank Welch lab members, Drs. Rudy Boonstra and Maydianne Andrade, and two anonymous reviewers for their constructive suggestions.

Conflicts of Interest: The authors declare no conflict of interest. The funders had no role in the design of the study; in the collection, analyses, or interpretation of data; in the writing of the manuscript, or in the decision to publish the results.

\section{References}

1. McKechnie, A.E.; Lovegrove, B.G. Avian facultative hypothermic responses: A review. Condor 2002, 104, 705-724. [CrossRef]

2. Ruf, T.; Geiser, F. Daily torpor and hibernation in birds and mammals. Biol. Rev. 2015, 90, 891-926. [CrossRef] [PubMed]

3. McNab, B.K. The Energetics of Endotherms. Ohio J. Sci. 1974, 74, 370-380. Available online: https://kb.osu. edu/handle/1811/22251 (accessed on 29 November 2018).

4. Aschoff, J. Thermal conductance in mammals and birds: Its dependence on body size and circadian phase. Comp. Biochem. Physiol. Part A Physiol. 1981, 69, 611-619. [CrossRef]

5. Prinzinger, R.; Preßmar, A.; Schleucher, E. Body temperature in birds. Comp. Biochem. Physiol. Part A Physiol. 1991, 99, 499-506. [CrossRef]

6. Hiebert, S.M. Seasonal Differences in the Response of Rufous Hummingbirds to Food Restriction: Body Mass and the Use of Torpor. Condor 1991, 93, 526-537. [CrossRef]

7. Suarez, R.K. Hummingbird Flight: Sustaining the Highest Mass-Specific Metabolic Rates among Vertebrates. Experientia 1992, 48, 565-570. [CrossRef]

8. Hixon, M. Energy maximizers and time minimizers: Theory and reality. Am. Nat. 1982, 119, 596-599. [CrossRef]

9. Welch, K.C., Jr.; Bakken, B.H.; Martinez del Rio, C.; Suarez, R.K. Hummingbirds fuel hovering flight with newly ingested sugar. Physiol. Biochem. Zool. 2006, 79, 1082-1087. [CrossRef]

10. Welch, K.C., Jr.; Chen, C.C. Sugar flux through the flight muscles of hovering vertebrate nectarivores: A review. J. Comp. Physiol. B 2014, 184, 945-959. [CrossRef]

11. Suarez, R.K.; Lighton, J.R.; Moyes, C.D.; Brown, G.S.; Gass, C.L.; Hochachka, P.W. Fuel selection in rufous hummingbirds: Ecological implications of metabolic biochemistry. Proc. Natl. Acad. Sci. USA 1990, 87, 9207-9210. [CrossRef] [PubMed]

12. Karasov, W.H.; Phan, D.; Diamond, J.M.; Carpenter, F.L. Food Passage and Intestinal Nutrient Absorption in Hummingbirds. Auk 1986, 103, 453-464. Available online: http:/ / www.jstor.org/stable/4087116 (accessed on 4 October 2018).

13. Calder, W.A.; Booser, J. Hypothermia of broad-tailed hummingbirds during incubation in nature with ecological correlations. Science 1973, 180, 751-753. [CrossRef]

14. Hiebert, S.M. Time-dependent thresholds for torpor initiation in the rufous hummingbird (Selasphorus rufus). J. Comp. Physiol. B 1992, 162, 249-255. [CrossRef] [PubMed]

15. Hainsworth, F.R.; Collins, B.G.; Wolf, L.L. The Function of Torpor in Hummingbirds. Physiol. Zool. 1977, 50, 215-222. Available online: https:/ / www.jstor.org/stable/30155724 (accessed on 8 May 2018). [CrossRef]

16. Lasiewski, R.C. Oxygen Consumption of Torpid, Resting, Active, and Flying Hummingbirds. Physiol. Zool. 1963, 36, 122-140. [CrossRef]

17. Krüger, K.; Prinzinger, R.; Schuchmann, K.L. Torpor and metabolism in hummingbirds. Comp. Biochem. Physiol. Part A Physiol. 1982, 73, 679-689. [CrossRef]

18. Weber, J.-M. Metabolic fuels: Regulating fluxes to select mix. J. Exp. Biol. 2011, 214, 286-294. [CrossRef]

19. Calder, W.A.; Calder, L.L.; Frazier, T.D. The hummingbird's restraint: A natural model for weight control. Experientia 1990, 46, 999-1002. [CrossRef]

20. Powers, D.R. Diurnal Variation in Mass, Metabolic Rate, and Respiratory Quotient in Anna's and Costa's Hummingbirds. Physiol. Zool. 1991, 64, 850-870. Available online: http://www.jstor.org/stable/30158211 (accessed on 8 May 2018). [CrossRef] 
21. Prinzinger, R.; Schäfer, T.; Schuchmann, K.L. Energy metabolism, respirtory quotient and breathing parameters in two convergent small bird species: The fork-tailed sunbird Aethopyga christinae (nectariniidae) and the chilean hummingbird Sephanoides sephanoides (trohilidae). J. Therm. Biol. 1992, 17, 71-79. [CrossRef]

22. Duke, G.E. Gastrointestinal physiology and nutrition in wild birds. Proc. Nutr. Soc. 1997, 56, 1049-1056. [CrossRef]

23. Carpenter, F.L.; Hixon, M.A.; Hunt, A.; Russell, R.W. Why hummingbirds have such large crops. Evol. Ecol. 1991, 5, 405-414. [CrossRef]

24. Hainsworth, F.R. Evaluating Models of Crop Emptying in Hummingbirds. Auk 1989, 106, 724-726. Available online: https: / / www.jstor.org/stable/4087684 (accessed on 5 October 2018).

25. Hainsworth, F.R.; Wolf, L.L. Crop volume, nectar concentration and hummingbird energetics. Comp. Biochem. Physiol. Part A Physiol. 1972, 42, 359-366. [CrossRef]

26. Gass, C.L.; Romich, M.T.; Suarez, R.K. Energetics of hummingbird foraging at low ambient temperatures. Can. J. Zool. Can. Zool. 1999, 77, 314-320. [CrossRef]

27. Suarez, R.K.; Herrera-M, L.G.; Welch, K.C., Jr. The sugar oxidation cascade: Aerial refueling in hummingbirds and nectar bats. J. Exp. Biol. 2011, 214, 172-178. [CrossRef]

28. Bucher, T.L.; Chappell, M.A. Respiratory exchange and ventilation during nocturnal torpor in hummingbirds. Physiol. Zool. 1997, 70, 45-52. [CrossRef]

29. Kleiber, M. The Fire of Life. An Introduction to Animal Energetics; Huntington, Robert Kreiger: New York, NY, USA, 1975.

30. Lighton, J.R.B. Measuring Metabolic Rates: A Manual for Scientists; Oxford University Press: Oxford, UK, 2008; ISBN 0195310616.

31. Levin, E.; Lopez-Martinez, G.; Fane, B.; Davidowitz, G. Hawkmoths use nectar sugar to reduce oxidative damage from flight. Science 2017, 355, 733-735. [CrossRef]

32. Lighton, J.R.B.; Bartholomew, G.A.; Feener, A.D.H., Jr. Energetics of Locomotion and Load Carriage and a Model of the Energy Cost of Foraging in the Leaf-Cutting Ant Atta colombica Guer. Physiol. Zool. 1987, 60, 524-537. [CrossRef]

33. Welch, K.C.; Péronnet, F.; Hatch, K.A.; Voigt, C.C.; McCue, M.D. Carbon stable-isotope tracking in breath for comparative studies of fuel use. Ann. N. Y. Acad. Sci. 2016, 1365, 15-32. [CrossRef] [PubMed]

34. Phillips, D.L.; Koch, P.L. Incorporating concentration dependence in stable isotope mixing models. Oecologia 2002, 130, 114-125. [CrossRef] [PubMed]

35. Welch, K.C., Jr.; Suarez, R.K. Oxidation rate and turnover of ingested sugar in hovering Anna's (Calypte anna) and rufous (Selasphorus rufus) hummingbirds. J. Exp. Biol. 2007, 210, 2154-2162. [CrossRef] [PubMed]

36. Chai, P.; Chang, A.C.; Dudley, R. Flight Thermogenesis and Energy Conservation in Hovering Hummingbirds. J. Exp. Biol. 1998, 201, 963-968. Available online: https://www.ncbi.nlm.nih.gov/pubmed/9487101 (accessed on 8 May 2018).

37. Welch, K.C.; Myrka, A.M.; Ali, R.S.; Dick, M.F. The Metabolic Flexibility of Hovering Vertebrate Nectarivores. Physiology 2018, 33, 127-137. [CrossRef] [PubMed]

38. Chevalier, M.M.; Wiley, J.H.; Leveille, G.A. Effect of dietary fructose on fatty acid synthesis in adipose tissue and liver of the rat. J. Nutr. 1972, 102, 337-342. [CrossRef] [PubMed]

39. McWilliams, S.R.; Guglielmo, C.; Pierce, B.; Klaassen, M. Flying, fasting, and feeding in birds during migration: A nutritional and physiological ecology perspective. J. Avian Biol. 2004, 35, 377-393. [CrossRef]

40. Powers, D.; Brown, A.; Van Hook, J. Influence of Normal Daytime Fat Deposition on Laboratory Measurements of Torpor Use in Territorial versus Nonterritorial Hummingbirds. Physiol. Biochem. Zool. 2003, 76, 389-397. [CrossRef]

41. Calder, W.A. Temperature Relationships and Nesting of the Calliope Hummingbird. Condor 1971, 73, 314-321. [CrossRef]

42. Suarez, R.K. Premigratory fat metabolism in hummingbirds: A Rumsfeldian approach. Curr. Zool. 2013, 59, 371-380. [CrossRef]

(C) 2019 by the authors. Licensee MDPI, Basel, Switzerland. This article is an open access article distributed under the terms and conditions of the Creative Commons Attribution (CC BY) license (http:/ / creativecommons.org/licenses/by/4.0/). 